\title{
A Comparative Study of Operating Angle Optimization of Switched Reluctance Motor with Robust Speed Controller using PSO and GA
}

\author{
V. Vasan Prabhu ${ }^{\dagger}$, V. Rajini*, M. Balaji* and V. Prabhu**
}

\begin{abstract}
This paper's focus is in reducing the torque ripple and increasing the average torque by optimizing switching angles of $8 / 6$ switched reluctance motor while implementing a robust speed controller in the outer loop. The mathematical model of the machine is developed and it is simulated using MATLAB/Simulink. An objective function and constraints are formulated and Optimum turn-on and turn-off angles are determined using Particle swarm optimization and Genetic Algorithm techniques. The novelty of this paper lies in implementing sliding mode speed controller with optimized angles. The results from both the optimization techniques are then compared with initial angles with one of them clearly being the better option. Speed response is compared with PID controller.
\end{abstract}

Keywords: Switched reluctance motor, Optimum angles, Genetic algorithm, Particle swarm optimization, Sliding mode controller, Speed control, Mathematical model, Objective function, Constraints, Boundary limits, Average torque, Torque ripple.

\section{Introduction}

In contrast to the widely held belief, the switched reluctance motors are one of the first electric motors invented. A variable reluctance stepper motor which has many common features as that of the present day SR (switched reluctance) motor and a prototype of SR motor were developed in the 1920s. But the low electromechanical energy conversion efficiency, large losses, structural problems and absence of power electronic switches rendered these motors ineffective in the long run. The subsequent development of DC machines switched the focus from SR machines [1,2].

The SR motors were re-invented in the $1960 \mathrm{~s}$ as an aftermath of the advancements made in power electronic switching technology [3]. An SR motor is developed which shares many features with the contemporary ones and can be addressed as a predecessor to the present day machine and since then the field of SR machines have become a key research area. In spite of considerable research progress, the SR motor is yet to be widely accepted in industries. The main pitfalls of the machine are acoustic noise and torque ripple which renders the machine impractical. The SR motor also demands unique control requirements which cannot be related to that of synchronous and induction machines [4-7]. Performance of a SR motor is mainly

$\dagger$ Corresponding Author: EEE department, Anand Institute of Higher Technology, Anna University, Chennai, India. (vasanprabhu@) gmail.com)

* EEE department, SSN college of Engineering, Chennai, India. ( \{rajiniv, balajim $\} @$ ssn.edu.in)

** EEE Department, AIHT, Anna University, Chennai, India. (vprbhu @gmail.com)

Received: April 11, 2014; Accepted: September 29, 2014 characterized by torque ripple minimization. Torque ripple has been minimized by current profiling or mechanical design optimization such as optimizing rotor and stator pole arcs. But a much better technique would be to optimize control parameters like turn-on angle, turn-off angle, reference current and size of hysteresis band [8-13]. The turn on and turn off angles are selected such that the torque ripple is minimum and average torque is maximum [14].

Minimization of torque ripple with PI speed controller is implemented. NSGA - II is used to determine optimum values of turn - on, turn - off angles of SRM and the integral and derivative constants for the PI speed controller. Also the advantages of NSGA - II like its ease of use, rapid convergence are discussed in detail [15]. But the main drawback is that for every optimum angle the gain of PI controller has to be changed. This increases the non linearity and complexity of the controller.

Two controllers, one each for turn on and turn off are suggested with performance optimization. The role of advance angle calculation in defining the optimal turn on angle, the impact of turn - on angle delayed and advanced beyond advance angle is discussed and experimentally validated. The criticality in selection of turn - off angle is stated [16]. SR motor with classical current converter is controlled using automatic turn off control. A PI speed control is implemented and results are shown both with and without speed control [17]. A self tuning speed control for SR motor is realized with optimal turn off angle to maintain maximum torque [18]. The above establishes the importance of optimization of turn-on and turn-off angles in reducing the torque ripple and the significance of a speed controller like PI controller. Also the need for a better speed controller can also be derived from careful 
analysis of the above works.

SR motor being non linear, a non linear control technique would suit well. Sliding mode and PID controls of a non linear system (Inverted Pendulum system) are compared and the importance of a state space system in sliding mode control is established. The superiority of sliding mode control is emphasized [19]. The application of sliding mode speed control to SR motor is both simulated and experimentally verified. This work suggests a feasible low cost sliding mode controller for a high performance speed regulation of SR Motors [20]. A Linear SR Motor is modeled and closed loop speed control with both PID and sliding mode control is implemented and the later is considered to be an appropriate controller [21]. A PI and sliding mode controller for SR motor are studied and robust controller is suggested for high performance speed regulation and tracking problem of SR motor. The PI controller is found to be not suitable as its dynamic response is poor. Overshoot and ripples were also found to be high [22]. Thus the superiority of sliding mode controller over PI controller is well established.

Optimization of turn-on and turn-off angles being finalized to be the ideal solution for reducing torque ripple, the question arises on which optimization tool to be used. The SR motor is modeled using a set of non linear equations and shape optimization is done with the help of Genetic Algorithm [23]. The turn on and turn off angles can be selected optimally by employing various algorithms. Optimization techniques like simulated annealing, Genetic Algorithm, Taguchi Algorithm are employed in SR motor applications [24, 25]. The best design parameters for switching circuits are determined using Genetic Algorithm. The two objective functions being maximization of efficiency and minimization of torque ripple [26]. Particle swarm optimization technique is applied to the optimal design of the 4/2 switched reluctance motor (SRM) [27]. Also the SR motor design is formulated as a multi objective constrained optimization problem and optimized using particle swarm optimization [28]. Hence Genetic algorithm and particle swarm optimization are taken as two main optimization tools.

The organization of this paper is as follows. Section 2 deals with the basic modeling and simulation of the SR Motor. Section 3 is dedicated towards implementation of the sliding mode control of the machine. Section 4 mainly considers the optimization techniques used here. The last section compares the results using the two optimized angles with initial non optimized angle,establishing one to be better.

\section{Modeling of SRMotor}

SR motor has been modeled using its electromagnetic and electro mechanical equations and has been simulated in MATLAB / Simulink environment [29, 30]. Not to be deceived by its plain sailing appearance, the mathematical modeling of the machine has to be done with meticulous approach. The double salient nature of the machine causes the inductance to change for unaligned to aligned position of rotor with reference to stator. This causes non linearity in torque and current. Hence reference frame theory cannot be applied for machine analysis. This makes the modeling of machine an uphill task. For less tedious modeling, few characteristics like magnetic saturation, leakage flux, fringing of flux around pole corners etc. are neglected. Each phase of the machine is also considered to be magnetically isolated from other phases.

The SR motor is modeled using the differential equations concerning voltage, motion and electromagnetic torque. The voltage equation is defined by

$$
v=i R+\frac{d \varphi}{d t}
$$

The equation 1 can be developed into

$$
\mathrm{v}=\mathrm{iR} \mathrm{R}_{\mathrm{m}}+\frac{\partial \varphi}{\partial \mathrm{i}} \frac{\mathrm{di}}{\mathrm{dt}}+\frac{\partial \varphi}{\partial \Theta} \frac{\mathrm{d} \Theta}{\mathrm{dt}}
$$

Where

$$
\frac{\partial \varphi}{\partial \mathrm{i}}-\mathrm{L}(\Theta, \mathrm{i}), \frac{\partial \varphi}{\partial \Theta}-\mathrm{Eb}(\Theta, \mathrm{i})=\mathrm{I} \frac{\mathrm{dL}(\Theta, \mathrm{i})}{\mathrm{dt}}
$$

Now rewriting equation 2 , we get

$$
v=i R_{m}+L(\Theta, i) \frac{d i}{d t}+I \frac{d L(\Theta, i)}{d t} \omega
$$

Where

$$
\omega=\frac{\mathrm{d} \Theta}{\mathrm{dt}}
$$

The torque equation governing the motor is given by

$$
\mathrm{T}=\frac{1}{2} \frac{\mathrm{dL}(\Theta, \mathrm{i})}{\mathrm{d} \Theta} \mathrm{i}^{2}
$$

From (4) we can conclude that the instantaneous torque is directly proportional to the square of the instantaneous current and the torque is also positive for increasing inductance and negative for decreasing inductance. Using MATLAB/SIMULINK mathematical model is constructed in accordance to (1)-(4). Fig. 1 shows the block diagram where a hysteresis controller of band limit $0.2 \mathrm{~A}$ and a classical power converter to drive the SR motor. Modelling of one phase of $8 / 6$ Switched reluctance motor is given in Fig. 2.

\section{Sliding Mode Control of SRM}

The sliding mode controller concerns the ordinary differential equations from (5)-(9) governing the system. 


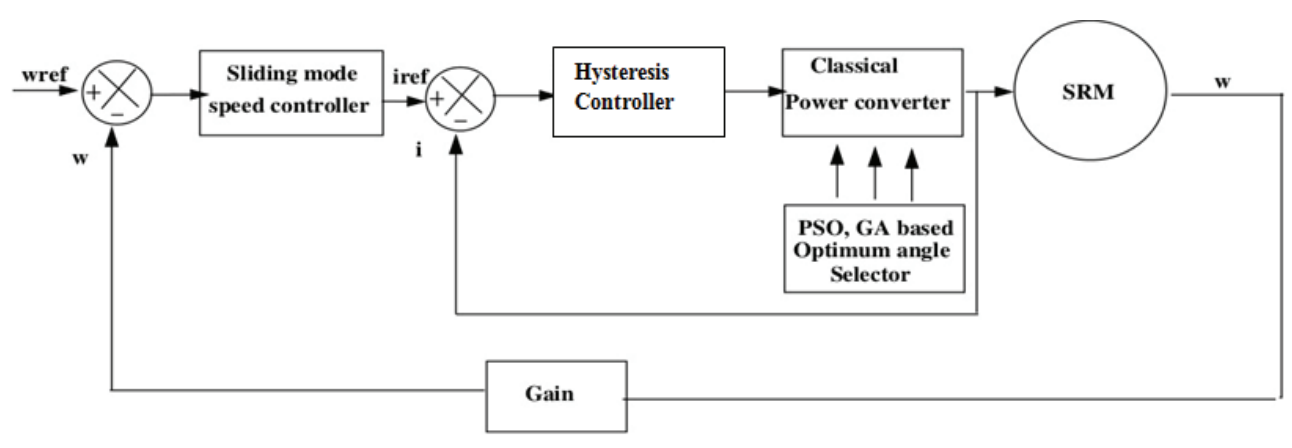

Fig. 1. Block diagram of $8 / 6$ SR Motor

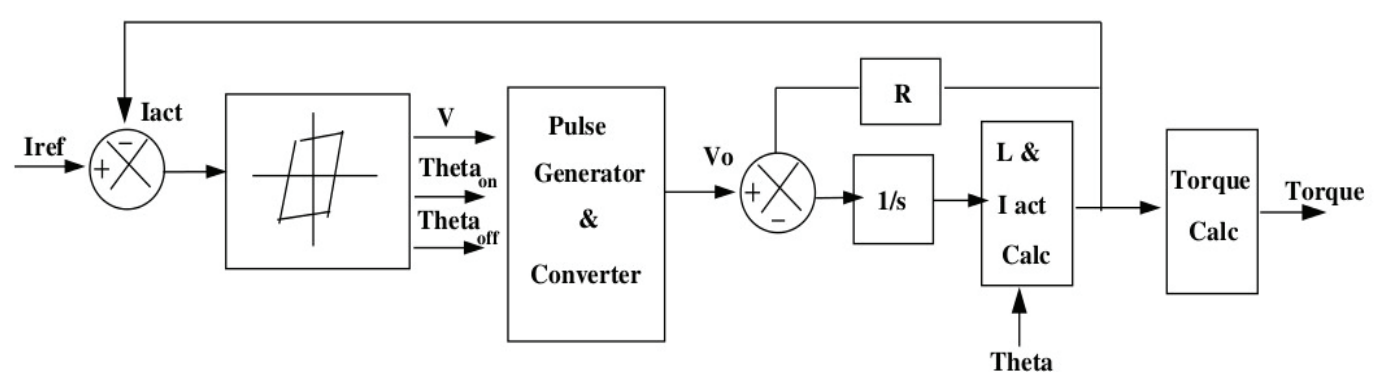

Fig. 2. Modelling of one phase of SR Motor

Due to the double salient nature of the machine the SR Motor is a highly non linear machine. Though the SR motor is seen as a nonlinear system there exists a particular section of the system trajectory which is found to be acceptable. The main idea of the sliding mode control is to apply a discrete control signal which forces the system to slide along this acceptable trajectory. For designing the controller, our utmost concern is regarding the definition of sliding surface. The sliding surface should be such that the motor is operating under the required condition while the system traverses along the sliding surface. The sliding surface is defined by the error quantity e. This error quantity e is obtained by comparing the rotor speed $\omega$ and the reference speed $\omega_{\text {ref. }}$ The defined sliding surface is a straight line, hence it can be represented by the straight line equation of the form $\mathrm{S}=0$. The line equation is given by

$$
S=\lambda \cdot e+\dot{e}
$$

The value of $\lambda$ should be such that it is large enough to cause exponential decay of speed error and hence asymptotic stability is achieved. When the value of $S$ is greater than zero the variables will decrease $\mathrm{S}$ and when $\mathrm{S}$ is less than zero, thevariables will increase it. Thus causes sliding motion inmaintaining the trajectory over S. For sliding mode condition to exist the following should be true

$$
\text { e. } \dot{e}<0
$$

This is called the existential condition for sliding mode control. The next step in controller design is to define a control law according to the need. This control law is selected such that chattering is nominal. The control law is given by

$$
U=\psi_{1} e+\psi_{2} \dot{e}
$$

Where

$$
\begin{aligned}
& \psi_{1}=\left\{\begin{array}{l}
\alpha_{1}, s x_{1}>0 \\
\beta_{1}, s x_{1}<0
\end{array}\right. \\
& \psi_{2}=\left\{\begin{array}{l}
\alpha_{2}, s \dot{x_{1}}>0 \\
\beta_{2}, s \dot{x_{1}}<0
\end{array}\right.
\end{aligned}
$$

While the term $\psi_{2} \dot{e}$ is introduced to reduce the noise and disturbance. The terms $\psi_{1}$ and $\psi_{2}$ can be determined using the following existential conditions,

$$
\begin{gathered}
\alpha_{1}>0, \beta_{1}<0 \\
\alpha_{2}>\left|\frac{\lambda-a}{b}\right|, \beta_{2}<\left|\frac{\lambda-a}{b}\right|
\end{gathered}
$$

where

$$
a=\frac{B}{J}, b=\frac{B}{J^{2}}
$$

Using the equations and existential conditions the block for Sliding mode control is modeled.

\section{Optimization of Switching Angles}

The stator winding is energized when the rate of change of inductance is positive and de-energized when rate of 
change of inductance approaches zero i.e. the inductance becomes constant. Thus the control strategy should be such that the current in the stator winding should be its rated value during turn on and should reach zero during turn off. But achieving instantaneous rise and fall in current is next to impossible for a non ideal machine. Hence the stator winding is energized at a turn on angle which is a little before the positive change of inductance and de-energized at a turn off angle which is fifteen degrees from the turn on angle for a $8 / 6 \mathrm{SR}$ motor. The advance angle calculation is given by the following Eqs. (10)-(12)

$$
\begin{gathered}
\theta_{o n}=\theta_{x}-\left[\frac{L_{u} I_{r} \omega_{r}}{V_{d c}}\right] \\
\theta_{o f f}=\theta_{x}+\left(2 . \theta_{s}-\theta_{e}\right)\left[1-\frac{\theta_{01}}{\theta_{e}}\right] \\
\Theta_{a d v}=\frac{L_{m i n} I_{r}}{V}
\end{gathered}
$$

Our main idea is to select this turn on and turn off angles such that the average torque is maximized and the torque ripple is minimized. This is considered as an optimization problem. For an optimization problem we seek for the best value of an objective function

This best value can be either maximized or minimized. But in a multi objective optimization problem there is more than one function which needs to be optimized. Fig. 3 shows the inductance profile of 8/6 SRM. Which gives the population around the operating regions. This multi objective optimization problem can be approached either by making a linear combination of the constraints which are assigned different weights and the function is then minimized or an entire population of possible solutions go through a process of evolution. Convergence is said to occur when the solution no longer evolves. This is the basis of the much discussed Genetic Algorithm technique.

\subsection{Genetic algorithm (GA)}

GA is a subset of evolutionary algorithms which performs systematic random search in determining the best possible solution. GA involves the population of individuals representing the chromosomes and each of the individuals is subjected to a series of evolution involving crossovers and mutations. This usually involves the following steps.

i. Evaluation of Initial fitness of all individuals in the population.

ii. Updating this population by performing operations like convergence and mutations.

iii. This updated population is the new population and the iteration is repeated.

To implement genetic algorithm as the tool for selecting optimum angles, our fore most concern lies in formulating the objective function. The objective function should be formulated such that the average torque should be maximum and the torque ripple should be minimum. The objective function is given in (13)

$$
f(x)=A x_{1}+B x_{2}
$$

Where $\mathrm{x}_{1}$ and $\mathrm{x}_{2}$ corresponds to maximization and minimization functions of average torque and torque ripple respectively. A and B are weightage constants. This A and $B$ should be selected such that the sum of $A$ and $B$ equals to one. A minus sign is introduced for maximization function. As seen earlier, in (14) the main constraint to be introduced is that the turn off angle should be fifteen degrees from the turn on angle.

$$
\Theta o f f-\Theta o n=\frac{N s-N r}{N r N s} * 360^{\circ}
$$

where

$$
\mathrm{T}_{\text {on }} \geq 0^{\circ}, \mathrm{T}_{\text {off }} \leq 30^{\circ}
$$

for $8 / 6 \mathrm{SR}$ machine in motoring mode of operation.

Genetic algorithm tool in MATLAB is utilized in calculating the optimum angles based on the above objective functions and constraints. Initial population of 30 is considered with a roulette selection function, uniform mutation, 0.8 crossover, rank scaling function and a generation limit of 100 .

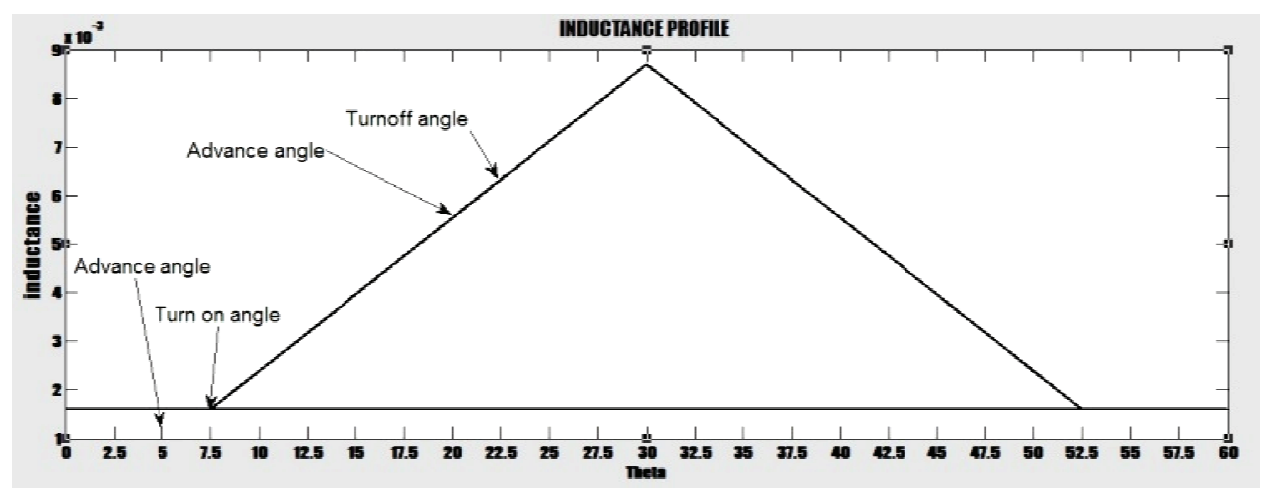

Fig. 3. Per phase Inductance profile of $8 / 6$ SR Motor 


\subsection{Particle swarm optimization (PSO)}

PSO developed by James Kennedy and Russell Eberhart, considers particles flying through $\mathrm{n}$ dimensional search space. Also each particle is considered to be a candidate solution to the optimization problem. Each dimension of each particle's initial position vector is randomly selected from a uniform distribution of feasible values. Velocity vectors are similarly initialized from a uniform distribution on per dimension using a reasonable maximum velocity. Then the search is initiated. During the search the members of the swarm interact with each other such that the result is optimized. Two best values one for $\Theta_{\text {on }}$ and another for $\Theta_{\text {off }}$ is selected. These are the personal best values. Then the iteration is repeated and each iteration has personal best values. Of the total personal best values two values are selected and these are Global best values for $\Theta_{\text {on }}$ and $\Theta_{\text {off }}$. The iteration is repeated with personal best and global best values. For each iteration the particle velocity and positions are updated using the Eqs. (15 and 16)

$$
\begin{aligned}
& \operatorname{vel}[\mathrm{k}]=\operatorname{vel}[\mathrm{k}]+\mathrm{c}_{1} * \operatorname{rand}[\mathrm{k}]^{*}(\operatorname{prsnlbest}[\mathrm{k}]-\operatorname{prsnt}[\mathrm{k}]) \\
& +\mathrm{c}_{2}{ }^{*} \operatorname{rand}[\mathrm{k}] *(\text { glblbest }[\mathrm{k}]-\operatorname{prsnt}[\mathrm{k}]) \\
& \operatorname{prsnt}[\mathrm{k}]=\operatorname{prsnt}[\mathrm{k}]+\operatorname{vel}[\mathrm{k}]
\end{aligned}
$$

For best results the cognitive parameter $c_{1}$ and social parameter $\mathrm{c}_{2}$ are selected to be 1.4. The initial population is set to be 30 and no of iterations is fixed at 100 .

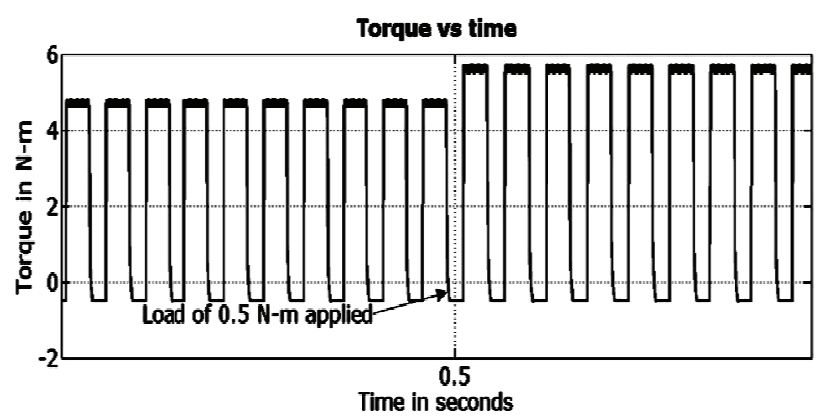

Fig. 4. Torque vs. time plot for initial angles 0 and 15

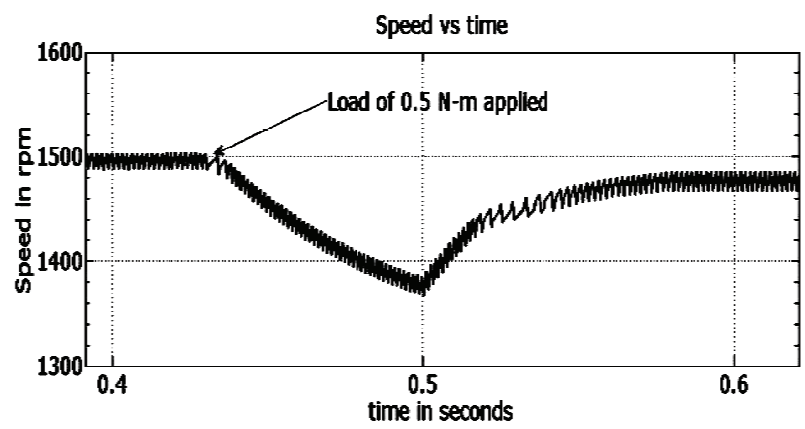

Fig. 5. Speed vs. time plot for initial angles 0 and 15

\section{Results and Discussion}

The speed control of SR motor model is implemented in the model shown Fig. 1 using MATLAB/SIMULINK tool in a Pentium (R) dual-core T4400@2.2 Ghz x 2 processor.

Optimized angle is generated using Genetic Algorithm and PSO algorithms written in MATLAB software. The torque ripple and average torque for optimum angles selected by both the techniques are tabulated in Table 1 and 2 and machine specifications are tabulated in Table 3. Final results are compared with the initial angle values. The simulation is run and results were plotted for speed, torque and phase current. The sliding mode controller is implemented for speed control.

To observe the difference in performance of the machine with and without optimum angle selection the machine is run with angles of 0 and 15 with a load of $0.5 \mathrm{~N}-\mathrm{m}$ applied and the results are taken. Figs. 4 and 5 shows the torque and speed waveform for the initial angle $(0,15)$ degree. We could see that the ripple content is more in torque waveform and the speed waveform rises smoothly and settles at around 0.3 seconds with no detectable peak overshoot. The average torque is calculated to be 2.68 while the torque ripple at steady state is almost 2 . This ripple is considerably large for the machine. Also from the torque waveform we can observe that the torque reaches zero for each phase excitation and this is not acceptable for a standard machine.

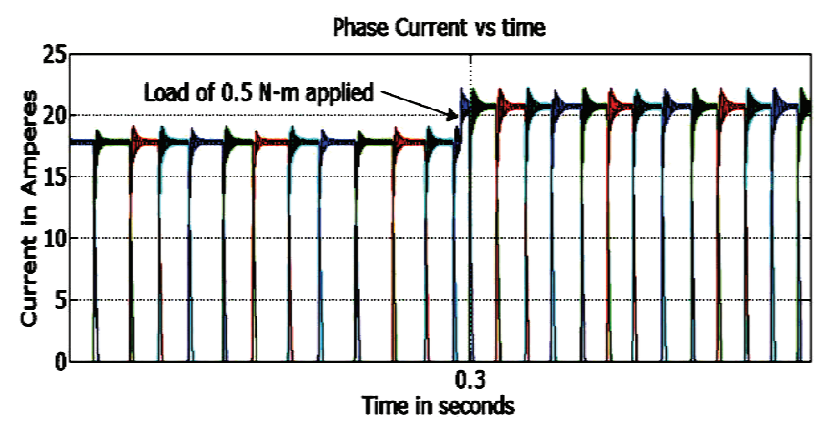

Fig. 6. Phase currents plot for optimized angles 7.5 and 22.5

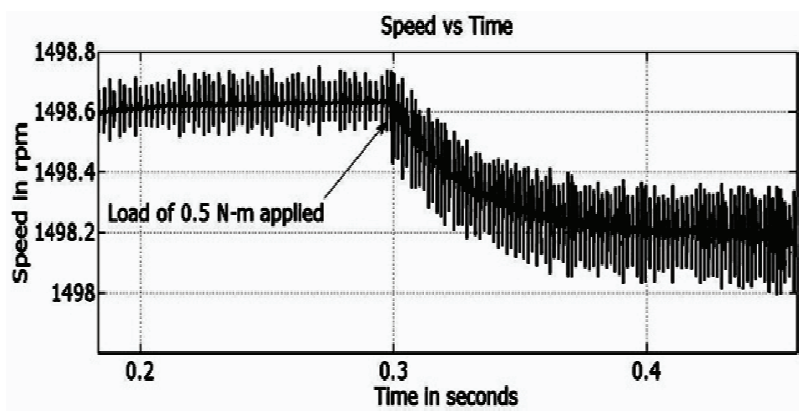

Fig. 7. Speed vs. time plot for optimized angles 7.5 and 22.5 
The optimized angles calculated by genetic algorithm are around 7.5 and 22.5. The machine is simulated with these angles and the phase current, speed and torque plots are shown in Figs. 6,7 and 8. The speed rises sharply and settles within 0.1 seconds. The average torque is found to be around 2.89. The torque ripple at steady state is calculated to be 0.7344 . The ripple is considerably reduced when compared with the initial angle set up.

The optimized angles calculated by Particle Swarm optimization is 8 and 23. The simulation is carried out with these angles and the results are taken as shown in Figs. 9, 10 and 11 . The phase current waveforms are similar to that of genetic algorithm results while the speed rise time is

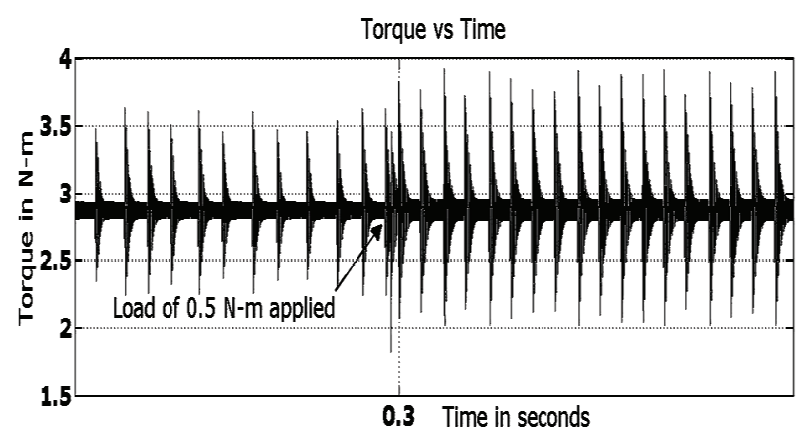

Fig. 8. Torque vs. time plot for optimized angles 7.5 and 22.5

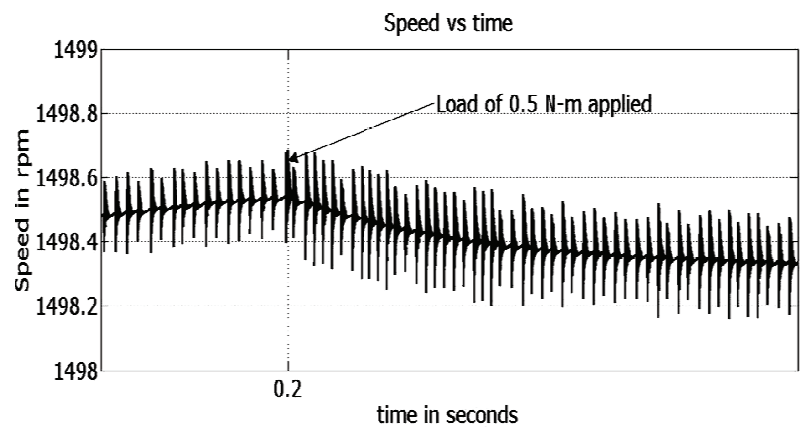

Fig. 10. Speed vs. time plot for optimized angles 8 and 23 more and settles around 0.2. The waveform is free of peak over shoot and has negligible ripple. The torque average is around 2.912 which is incremental from the Genetic results but huge difference can be seen in torque ripple. The ripple content is only around 0.497 .

SR Motor being a highly nonlinear machine, operating angle tuning increases the complexity in controller design. Sliding trajectory is designed for the upper and lower boundaries of the operating angle. Better speed response with minimum speed ripple, but in PID controller every operating angle needs separate gain values, speed response is comparatively low. Fig. 12 shows the speed response of sliding and PID controller with optimum

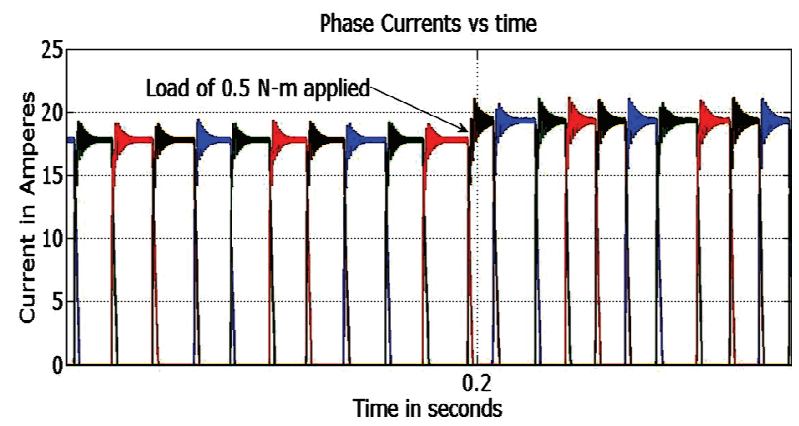

Fig. 9. Phase currents plot for optimized angles 8 and 23

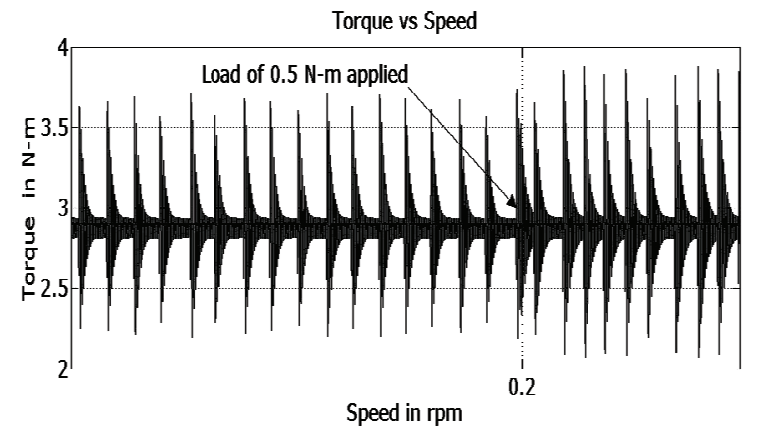

Fig. 11. Torque vs. time plot for optimized angles 8 and 23

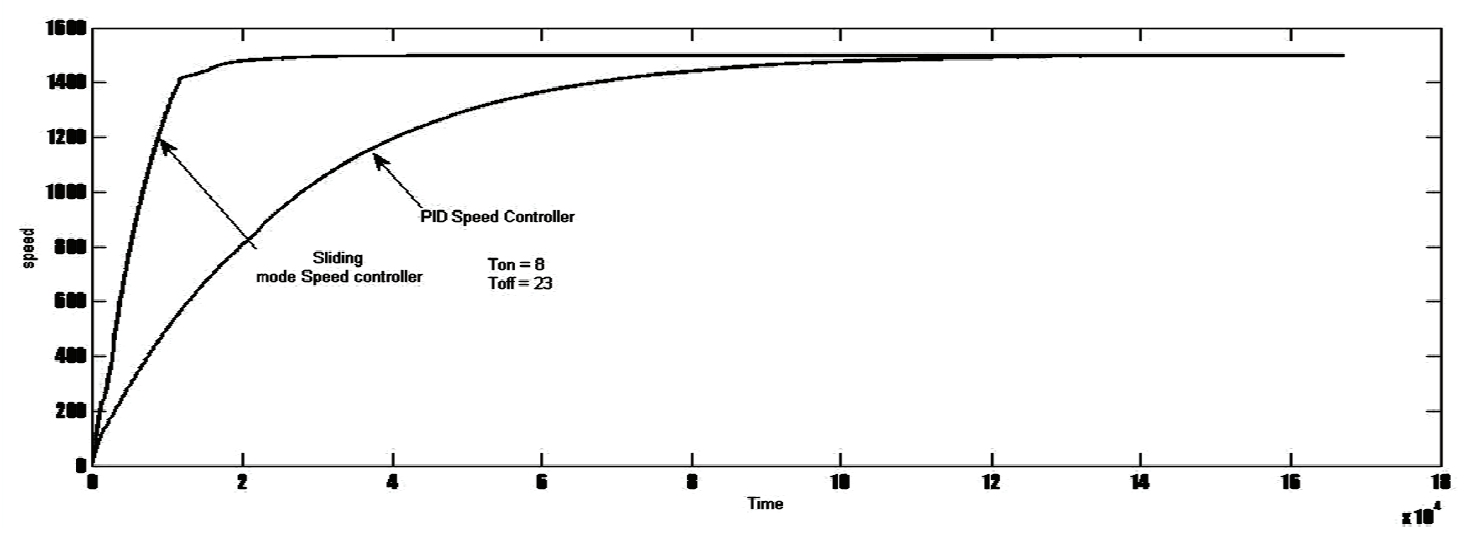

Fig. 12. Speed response curve for $8 / 6$ SR Motor with sliding mode and PID speed controller 
operating angle.

\subsection{Tables}

Table 1. Comparison of convergence factors

\begin{tabular}{c|c|c}
\hline & GA & PSO \\
\hline No of iterations & 51 & 46 \\
\hline Time & $79.56 \mathrm{sec}$ & $69.3 \mathrm{sec}$ \\
\hline Best value & 0.891 & 0.912 \\
\hline Worst value & 0.011 & 0.370 \\
\hline No of Runs & 20 & 20 \\
\hline
\end{tabular}

Table 2. vgTorque and Ripple values for GA and PSO

\begin{tabular}{c|c|c|c|c}
\hline Optimization Algorithm & $\mathrm{T}_{\text {on }}$ & $\mathrm{T}_{\text {off }}$ & $\mathrm{T}_{\text {avg }}$ & $\mathrm{T}_{\text {ripple }}$ \\
\hline Initial Angle & 0 & 15 & 2.680 & 1.958 \\
\hline GA & 7.5 & 22.5 & 2.890 & 0.734 \\
\hline PSO & 8 & 23 & 2.912 & 0.508 \\
\hline
\end{tabular}

Table 3.Machine Specifications

\begin{tabular}{c|c}
\hline Power Rating & $1 \mathrm{HP}$ \\
\hline Max.current & $16 \mathrm{~A}$ \\
\hline Speed & 1500 \\
\hline Stator poles & 8 \\
\hline Rotor poles & 6 \\
\hline Lmin & $1.6 \mathrm{mH}$ \\
\hline Lmax & $8.7 \mathrm{mH}$ \\
\hline Resistance/phase & $1.3 \mathrm{ohm}$ \\
\hline Stator pole arc & 22.5 \\
\hline rotor pole arc & 22.5 \\
\hline
\end{tabular}

\section{Conclusion}

The mathematical modeling of SR motor is performed and is simulated in MATLAB/SIMULINK environment. The optimum turn on and turn off angles are selected using Genetic and Particle Swarm optimization algorithms. Sliding mode speed controller is successfully implemented and the results obtained are found to be viable. These results are then compared with results taken with initial angles. For optimized angles the Torque average is larger and torque ripple is minimized with PSO algorithm providing the best and effective solution. The results with PSO are efficient to a larger degree compared with the initial angle setup while Genetic Algorithm providing the next best solution. Thus the angles of 8 and 23 are found to be the best possible solution for the given machine while 7.5 and 22.5 being the next best. Finally for the same optimum angle the sliding mode controller performance is compared with PID controller.

\section{Nomenclature}

$\begin{array}{ll}\mathrm{V} & \text { - Instantaneous voltage across each phase in } \mathrm{V} \\ \mathrm{i} & \text { - Instantaneous phase current in A } \\ \varphi & \text { - Flux linkage in phase windings in Weber - turns }\end{array}$
$\mathrm{R} \quad$ - Motor phase winding resistance in $\Omega$

- Rotor position

$\theta_{x}$ - Rotor position where pole corners start to overlap

$\theta_{\text {s }}$ - Stroke angle

$\theta_{\mathrm{e}}-$ Rotor angle interval for flux linkage to decay to zero

$\theta_{01}$ - Rotor angle interval from turn-on up to a position that current reaches its command value.

$\mathrm{L}(\theta, \mathrm{i})$ - instantaneous inductance

$\mathrm{E}_{\mathrm{b}}(\theta, \mathrm{i})$ - instantaneous back emf

$\omega, \omega_{\text {ref }}$ - speed and speed reference in radian/sec

$\mathrm{T}(\theta, \mathrm{i})$ - instantaneous torque in $\mathrm{N} / \mathrm{m}^{2}$

$\mathrm{S}$ - Sliding equation

$\lambda$ - slope of sliding line

e - speed error

$\dot{e} \quad$ - derivative of speed error

U - Control law

$\theta_{\text {adv }}$ - advance angle

B - Coefficient of friction in N-m-s/rad

$\mathrm{J}$ - Inertia of the motor in $\mathrm{kg}-\mathrm{m}^{2}$

vel[k] - velocity of the particle

prsnt[k] - solution of current particle

prsnlbest[k] - personal best solution

glblbest[k] - global best solution

rand $[\mathrm{k}]$ - random number

$\mathrm{c}_{1}$ and $\mathrm{c}_{2}$ - learning factors

\section{References}

[1] Mukhtar Ahmad, High Performance AC Drives, Springer, 2010, p.129.

[2] TJE Miller, Electronic Control of Switched Reluctance Machines, Newnes, 2001, p. 9.

[3] R. Krishnan, Switched Reluctance Motor Drives, Modeling, Simulation, Analysis, Design and Applications, CRC Press, 2001.

[4] Balaji, M.; Vaithilingam, C.A.; Kamaraj, V., "Torque ripple minimization in switched reluctance motor drives," Power Electronics, Machines and Drives, 2004. (PEMD 2004). Second International Conference on (Conf. Publ. No. 498), vol.1, no., pp. 104, 107 Vol. 1, 31 March-2 April 2004.

[5] Nasar, S.A., "D.C. -switched reluctance motor," Electrical Engineers, Proceedings of the Institution of, vol.116, no.6, pp.1048,1049, June 1969.

[6] Miller, T. J E, "Optimal design of switched reluctance motors," Industrial Electronics, IEEE Transactions on, vol.49, no.1, pp.15,27, Feb 2002.

[7] Krishnan, R.; Bedingfield, R. A., "Dynamic analysis of an SRM drive system," Industry Applications Society Annual Meeting, 1991., Conference Record of the 1991 IEEE, vol., no., pp. 265, 271, vol. 1, Sept. 28 1991-Oct. 41991.

[8] Moallem, M.; Ong, C.M.; Unnewehr, L.E., "Effect of rotor profiles on the torque of a switched reluctance motor," Industry Applications Society Annual Meeting, 
1990., Conference Record of the 1990 IEEE, vol., no., pp.247,253 vol.1, 7-12 Oct. 1990.

[9] Xu, Y.Z.; Zhong, R.; Chen, L.; Lu, S.L., “Analytical method to optimize turn-on angle and turn-off angle for switched reluctance motor drives," Electric Power Applications, IET, vol.6, no.9, pp.593,603, November 2012.

[10] Reinert, J.; Inderka, R.; Menne, M.; De Doncker, R.W., "Optimizing performance in switched reluctance drives," Applied Power Electronics Conference and Exposition, 1998. APEC '98. Conference Proceedings 1998., Thirteenth Annual, vol. 2, no., pp. 765, 770 vol. 2, 15-19 Feb 1998.

[11] Gribble, J.J.; Kjaer, P.C.; Cossar, C.; Miller, T.J.E., "Optimal commutation angles for current controlled switched reluctance motors," Power Electronics and Variable Speed Drives, 1996. Sixth International Conference on (Conf. Publ. No. 429), vol., no., pp. 87, 92, 23-25 Sept. 1996.

[12] Shun-Chung Wang; Wen-Han Lan, "Turn-on angle searching strategy for optimized efficiency drive of switched reluctance motors," Industrial Electronics Society, 2004. IECON 2004. 30th Annual Conference of IEEE, vol. 2, no., pp. 1873, 1878, Vol. 2, 2-6 Nov. 2004.

[13] Akhter, H.E.; Sharma, V.K.; Chandra, A.; Al-Haddad, $\mathrm{K}$., "Modeling simulation and performance analysis of switched reluctance motor operating with optimum value of fixed turn-on and turn-off switching angles," Power Electronics Specialist Conference, 2003. PESC '03. 2003 IEEE 34th Annual, vol. 1, no., pp. 397,402 vol. 1, 15-19 June 2003.

[14] Sheth, N. K.; Rajagopal, K. R., "Determination of optimum switching angles for speed control of switched reluctance motor drive syatem," IEEE Transactions on Magnetics, vol.39, no.5, pp. 3214, 3216, June 2004.

[15] L. Kalaivani, P. Subburaj, M. WilljuiceIruthayarajan, "Speed control of switched reluctance motor with torque ripple reduction using non-dominated sorting genetic algorithm (NSGA-II)," International Journal of Electrical Power and Energy Systems, Volume 53, December 2013, Pages 69-77.

[16] Mademlis, C.; Kioskeridis, I., "Performance optimazation in switched reluctance motor drives with online commutation angle control," Energy Conversion, IEEE Transactions on, vol. 18, no. 3, pp. 448, 457, Sept. 2003

[17] Nashed, M. N F, "Variable angle adjustable-high speed control with PI for SRM," World Automation Congress (WAC), 2010, vol., no., pp.1, 6, 19-23 Sept. 2010

[18] Jong-yunSeo; Hyun-Rok Cha; Hyong-yeol Yang; Jung-ChulSeo; Kwang-heon Kim; Young-Cheol Lim; Do-Hyun Jang, "Speed control method for switched reluctance motor drive using self-tuning of switching angle," Industrial Electronics, 2001. Proceedings. ISIE 2001. IEEE International Symposium on, vol. 2, no., pp. 811, 815, vol. 2, 2001.

[19] A.N.K. Nasir, R.M.T. Raja Ismail, M.A. Ahmad, "Performance comparision between sliding mode control and PD-PID controllers for a non linear inverted pendulum system," World Academy of Science, Engineering and Technology, Vol:46 2010-10-27.

[20] John, G.; Eastham, A.R., "Speed control of switched reluctance motor using sliding mode control strategy," Industry Applications Conference, 1995.Thirtieth IAS Annual Meeting, IAS '95., Conference Record of the 1995 IEEE \}, vol. 1, no., pp. 263,270 vol. 1, 8-12 Oct 1995.

[21] Zaafrane Wajdi, Kediri Jalel And Rehaoulia Habib., "Sliding Mode Current Control of Linear Switched Reluctance Motor," International Journal of Emerging Sciences, 3(2), 130-143, June 2013.

[22] Muhammad Rafiq, Saeed-ur-Rehman, Fazal-urRehman, QarabRaza Butt., "Performance Comparision of PI and SMC for speed control applications of SRM," European Journal of Scientific Research, Vol.50 No.3 (2011), pp.363-380.

[23] Naayagi, R. T.; Kamaraj, V., "A Comparative Study of Shape Optimization of SRM using Genetic Algorithm and Simulated Annealing," INDICON, 2005 Annual IEEE, vol., no., pp.596, 599, 11-13 Dec. 2005

[24] Owatchaiphong, S.; Fuengwarodsakul, Nisai H., "Multi-objective based optimization for switched reluctance machines using fuzzy and genetic algorithms," Power Electronics and Drive Systems, 2009. PEDS 2009. International Conference on, vol., no., pp. 1530, 1533, 2-5 Nov. 2009.

[25] Omekanda, A. M., "Robust torque- and torque-perinertia optimization of a switched reluctance motor using the Taguchi methods," Electric Machines and Drives, 2005 IEEE International Conference on, vol., no., pp. 521, 526, 15-15 May 2005.

[26] Mirzaeian, B.; Moallem, M.; Tahani, V.; Lucas, C., "Multiobjective optimization method based on a genetic algorithm for switched reluctance motor design," Magnetics, IEEE Transactions on, vol. 38, no. 3, pp. 1524,1527, May 2002.

[27] Phuangmalai, W.; Konghirun, M.; Chayopitak, N., "A design study of $4 / 2$ switched reluctance motor using particle swarm optimization," Electrical Engineering/ Electronics, Computer, Telecommunications and Information Technology (ECTI-CON), 2012 9th International Conference on, vol., no., pp. 1,4, 16-18 May 2012.

[28] Balaji, M.; Kamaraj, V., "Design optimization of Switched Reluctance Machine using Particle Swarm Optimization," Electrical Energy Systems (ICEES), 2011 1st International Conference on, vol., no., pp. 164, 169, 3-5 Jan. 2011.

[29] Soares, F.; Costa Branco, P.J., "Simulation of a 6/4 
switched reluctance motor based on Matlab/Simulink environment," Aerospace and Electronic Systems, IEEE Transactions on, vol. 37, no. 3, pp. 989, 1009, Jul 2001.

[30] Arumugam, R.; Lindsay, J.F.; Krishnan, R., "Sensitivity of pole arc/pole pitch ratio on switched reluctance motor performance," Industry Applications Society Annual Meeting, 1988., Conference Record of the 1988 IEEE, vol., no., pp. 50, 54, vol. 1, 2-7 Oct. 1988.

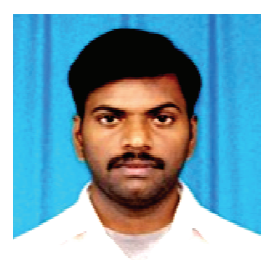

V. Vasan Prabhu Asst. professor in the department of Electrical and Electronics Engineering has 6 years of teaching and research experience. He received his $\mathrm{BE}$ and $\mathrm{ME}$ degrees in Electrical Engineering department from Anna University Chennai. He is currently doing research in SR machine control and his area of interest lies in special electrical machines, machine design, drives and control and artificial intelligence.

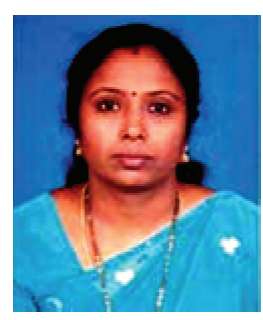

V. Rajini Professor in the Department of Electrical and Electronics Engineering has 18 years of teaching and research experience. She received her $\mathrm{BE}$ and ME (University Rank 1) degrees in Electrical Engineering from Annamalai University and $\mathrm{PhD}$ from Anna University Chennai. She has published over 35 research publications in referred journals and international conferences. She has received best paper awards in various conferences. She has received Best paper awards in various conferences. Best teacher awards and CTS - SSN Best Faculty Award.

M. Balaji, He received his B.E. (EEE) degree first class with distinction from Annamalai University, M.E. Power Electronics and Drives from Sri Venkateshwara College of Engineering, and $\mathrm{PhD}$ from Anna University Chennai. His areas of interest include Electrical Machines, Power Electronics, Switched reluctance motor, optimization algorithms.

V. Prabhu, received his Bachelor's Degree in electrical and electronics engineering in the year 2003. Doing master degree in Anna University, Chennai. He has immense experience in Iron and Steel industry. 